\title{
Adivasi aesthetic knowing: A duographic account
}

Richard Hickman and Pallawi Sinha

\begin{abstract}
Using the different voices of the mentor and mentee, we engage with the notion of creating and conferring aesthetic significance as it occurs in the everyday lives of everyday peoples. We investigate how the arts empower marginalized 'voice' by enabling multimodal expressions and access to information that other methods may not elicit. This paper takes the form of a 'duography', reporting an empirical study that focused upon an Adi Jan Jaati (Particularly Vulnerable Tribal Group) of Jharkhand, in North Eastern India. In particular, we focus upon this indigenous community's epistemic and aesthetic practices. The paper thus offers discussions on how aesthetic experiences and activities are essential means of being, of engagement and communication, and of (re)building trust with the community. We conclude by demonstrating the relevance of everyday aesthetics for the development of sustainable educational systems and future citizenship. Standing back, we acknowledge the reciprocal learning that occurs between the researcher and the 'researched', the doctoral student and supervisor.
\end{abstract}

Keywords: indigenous research, postcolonialism, Self-Other, education, arts and everyday aesthetic practices, place-making, localization, educational ecology, and duography. 


\section{Adivasi Aesthetic Knowing: A duographic account}

Richard Hickman, University of Cambridge

Mailing address c/o University of Cambridge

Faculty of Education,

Hills Rd., Cambridge CB2 8PQ

UK

Email:rdh27@cam.ac.uk

Pallawi Sinha, University of Cambridge

Mailing address c/o University of Cambridge

Faculty of Education,

Hills Rd., Cambridge CB2 8PQ

UK

Email:ps527@cam.ac.uk 


\section{Introduction}

In this paper, we focus on aesthetic significance created and conferred (Hickman, 2005) by an indigenous community of India, weaving in our intellectual and epistemological journey (leading to a doctoral thesis) in the form of a duography. Duography is defined as a retrospective written account that two people provide of selected events or ideas taken from their lives. We adopt Diamond and Mullen's (1996) suggestion that the development of graduate students as emerging researchers may be promoted through joint inquiry and a dual approach to presenting findings. Pallawi is the (former) mentee who was responsible for designing and implementing research and Richard is the (former) mentor, responsible for guiding and critiquing both the methodological and substantive aspects of the research reported here.

Diamond and Mullen (1996) provide a paradigm example of 'duography', exploiting their former mentor-mentee relationship in exploring a form of qualitative research that extends ways of thinking about and practising the mentorship of graduate students: 'through reciprocal sharing, greater overall insight is achieved and personal perspective is strengthened' (Diamond \& Mullen, 1996, p. 18). Such reciprocity of sharing is reflected in the authors' conversations, leading to the design of the study, and in the co-construction of knowledge with the indigenous people.

The study was conducted with the participation of twenty-three Hill Sabar ${ }^{i}$ families from six associated hamlets, and three neighboring Sabar villages in Jharkhand, India. Commencing in August 2014, the investigation was undertaken over a period of ten months. This marginalized community was approached due to their sustained disengagement from the formal systems of 
education in India, and to ascertain their epistemic traditions and priorities. We were inquisitive too, to investigate the status of arts in such 'depressed' (Gandhi, 1932) or deprived communities.

\section{Excerpt 1- Initial conversations}

Pallawi: "Acknowledging difference (Delva et al. 1999) and ascertaining indigenous voice is a primary concern for this study but the available literature on methodology and ethics do not serve such purposes, holistically..."

Richard: "Pallawi, your Master's thesis was a very worthwhile and valuable piece of work that gave us some insight into the lives of dispossessed children in India. It also gave you an introduction into educational research and the accompanying issues concerning ethical matters and methodological rigor. You should see your PhD as a kind of apprenticeship that develops from your master's dissertation, with a keen focus on both method and methodology..."

The authors locate the study within the notions of marginalisation, indigeneity, postcolonialism and emancipation, which necessitated careful consideration of its methodological priorities. In doing so, we acknowledge our own positions of power as dominant outsiders. Research was thus articulated as a process rather than 'typology of behaviours' (Delva et al., 2010, p.3) with a priority to diminish barriers of privilege, literacies, and codes of practice. This has led to our subsequent adaptation of ethnomethodology (EM) alongside audio-visual and spatial participatory tools; these tools were designed contextually to generate 'thick' data from a site where dependency on verbal and textual literacies alone would have been unreliable. In a seminal work, Garfinkel (1963) asserts that the goal of the sociologist is to reveal the underlying features of everyday activities, and to treat as problematic that which is taken for granted. In order to understand the commonsense everyday world, one must examine mundane methods and taken-for-granted phenomena. 


\section{Excerpt 2 - Locating Methodology}

Richard: "We need to think carefully about not just the methods that you intend to use, but also the underpinning theoretical framework...

Ethnomethodology is one of those polysyllabic words that academics seem to like to use that are quite easy to understand and interpret, just by looking at its obvious etymology: ethno = people; method = method; ology = study of (see Garfinkel, 1974). It refers to the study of ordinary members of society in everyday situations and in which they use commonsense approaches to navigate those situations. Ethnomethodology examines how ordinary people make sense of their social world and the 'accounts' they give. Accounts are ways in which people explain social situations they are tied to, particular contexts and constructs built from past interactions. Although some contemporary sociologists believe that the scope of analysis used in ethnomethodology is too narrow, it looks like this is the way forward for you.

In terms of methods used within the ethnomethodological approach, open-ended or in-depth interviews involving participant observation are favored, using video and what are referred to as 'breaching experiments'. Breaching experiments involve violating the everyday rules as a technique for discovering social order through its disruption - social reality is disrupted to shed light on the methods by which people construct social reality. In most ethnomethodological studies, the researcher enters a social setting, violates or breaches the rules that govern it, and studies how the actors in the setting deal with the breach. In your case, Pallawi, the very act of entering into the physical realm of the Sabar is in itself a significant breach of the normal social setting."

Pallawi: "Ethnomethodology seems appropriate for the study since members lead the research and the researcher here by systematically introducing the processes and practices of their lived-world. This would transfer some power of the study to the Sabar. Nonetheless, our information would be incomplete and unrepresentative of indigenous educational traditions, key concepts, 'imaginings' and concerns if the focus were primarily on the processes and verbal expressions. This may be overcome with participatory tools that allow for a diversity of expressions and create spaces for reconceptualizing education."

Using a 'duographic' approach, we have had the opportunity to think and converse freely.

These understandings have helped develop critical analyses of constructs and engender creative conversations. Hereby, we offer a brief introduction to the Sabar before elaborating discussions on how everyday aesthetic practices may emerge as tools for engagement and authentic enquiry. 


\section{Retelling the Sabar Story}

The study was the first opportunity for Pallawi, the fieldworker, to engage with the Sabar peoples, and concomitantly, the first encounter the Sabar have had with a researcher. The researcher's position, as a female investigator and a privileged outsider seeking the Sabar voice, created intrigue amongst the people but the dualities of paradigm (Self-Other, dominant-dominated, empowered-marginalized) also produced barriers that had to be overcome. One such barrier was language, which Pallawi learnt for three months before entering the site. However, the community no longer used the Sabar language of Kharia; instead, a dialect derived from the neighboring states of Orissa and Bengal was employed. Contrarily, this was helpful since Pallawi had some familiarity with these languages. The dialect was therefore learnt on-site, drawing upon Sabar language references from the commencement of study. During Pallawi's initial visits, the Sabar women and children would run into the jungles upon seeing her approach their hamlets. It took a month of her climbing uphill to their houses, elaborating research intentions and contextualizing educational constructs that build a gradual relationship of trust.

\section{Fieldnotes 1:}

To reach these tolas (hamlets), I would depart from my hostel by 4:30-6:00am and adopt various modes of transport. As I diverted into pagdandi's (crude pathways) meandering into the luscious vista, the hustle bustle of the highway was observably contrasted by the calm of the early morning. Once at the base site, Dengham, I trekked $10-12 \mathrm{kms}$ into the newly forested hills where these hamlets were spread out. This one sided-journey was approximately $50-55 \mathrm{kms}$, and would take me two and a half to three hours; it is interesting to note that this daily effort of uphill climbing had provided authentic access into the community when the community leader remarked, 'You are like us. You can climb like us', and would relate this with pride to other community members.

As the site made evident, 'five Js' have been identified as the crucial elements of existence; these are Jal (water), Jungle (forests), Janvar (animals), Jan (people) and Jameen (earth). 
Sabar people's connections to these are not merely practical or materialist but also spiritual.

Assembled hamlets and neighboring villages may have familial relationships but all elderly are referred to in familial terms, and respected and cared for communally. The Sabar wake up by 3:00 am to start their daily chores and leave for work in the jungles by 7:30 am, only to return by sunset. Their labor-intensive work usually consists of collecting medicinal herbs and plants, wood for fire, house-making and selling at markets, and bamboo for making brooms, wooden utensils and hunting tools. As a fairly isolated group of peoples, to Pallawi they appeared warm but extremely shy of strangers, and wary of new technology and foreign sounds. For example, when she was showing children how to rewind the finished camera reel, it made a whirring sound. Upon hearing this unfamiliar sound two of the children threw their cameras and ran away.

\section{Excerpt 3- Acknowledging difference}

Pallawi: "While the dominant world disregards epistemic difference, acknowledging indigenous 'ways of being' (communality, ecological and communal behavior and place-making) would accelerate their process of healing. My immediate concern is also to reinforce Sabar people's confidence in their own knowledge and practice since they often referred to themselves as boka (naïve, useless person), a term applied by the dominant society". Richard: "I have found that when people are engaged in 'creating aesthetic significance', in making, their self-esteem is heightened. If we can demonstrate to the Sabar people that their engagement with traditional making and engagement with the arts is of more general value, then we can perhaps assume that heightened self-esteem would follow and the notion of being 'boka' would diminish..."

\section{Sabar aesthetics in everyday reality}

The Sabar do not distinguish between art, craft and design but have a distinct inclination towards 'making', such as wooden utensil-making, bow-arrow and trap-making. In addition, dancing, singing and storytelling are some of the everyday activities that the Sabar engage 
with as a means of communal bonding and demonstrating reverence for Nature. Perhaps more importantly, such intellectual and creative pursuits are a conduit for the intergenerational passage of knowledge, practices, skills and beliefs. An excerpt of one such conversation (text box, below) about what it meant to be Sabar, illustrates how aesthetic or socio-cultural practices can empower.

\section{Excerpt 4 - Sabar sense of self through aesthetic and cultural practices}

Male 1: ...house-making, red-ant chutney, living and playing in the jungles with jungle animals and storytelling, all are our culture.

Male 2: Karam puja (veneration), dancing and singing, hunting and sacrificing cocks, makes us Sabar.

Female 1: Now we celebrate Diwali and Dussehra, too. But we worship trees, animals, water and the jungles. Other people have gods, these are our gods.

Male 3: Our culture also has a lot of dancing, mandol (drum) playing and handiya (fermented rice drink) drinking. Especially during Karam puja, if there is not a lot of singing and dancing around the tree branch we sow, it will wilt and die. We will show you these...

Female 3: Maghi puja! That is a very special parab (festival) as well; we repair and replaster our houses then, make floral paintings with grounded rice to welcome our ascendants, good omen and the gods to our houses. We cannot be Sabar if we don't follow these.

The conception of art as an integral human activity is not a novel idea that we conjecture but one located in wider scholarship of anthropology, medicine, participatory and indigenous research, and arts education, respectively (see Dissanayake, 1999; Dutton, 2009; Sacks, 2008; Thomson, 2008; Smith, 1999; Harland et al, 2000). Dissanayake (1999) posits, 'culture and their institutions, practices, and artefacts - different as they might be - are means of satisfying fundamental human needs' and enable our proclivity 'to bond with others, to imitate [...] to resist [...] to accept beliefs of our associates' (p.8). Likewise, the authors' shared interest in art, aesthetic significance and arts education enabled diverse conversations, which were 
fundamental in initiating the mentor-mentee relationship and facilitated development of their own artistic and educational practices.

\section{THE SABAR AESTHETICS OF DOING, BEING AND KNOWING}

Sabar aesthetic understanding, 'distinct from personal enjoyment' [starts with] 'the soil, air, and light, out of which things esthetically admirable arise' (Dewey, 2005, p.11). This is evident in everyday life and ceremonial occasions where visceral techniques, forms and materials are employed towards producing culturally representational and symbolic artefacts; these include the following: utensil making, cleansing and colouring of pebbles for rituals, veneration objects made from clay, hay, and flowers, whitewashed burial sites with tapered headstones and toys children construct from available materials. It is evident from the ideas portrayed here, that even in (what we, the majority world, consider) conditions of economic and social deprivation, the Sabar reveal the innate human propensity to pursue aesthetic significance. Simultaneously, audio-visual and spatial participatory tools ${ }^{1}$ established scaffolds for deconstruction of Sabar educational constructs by the Sabar themselves.

\section{Fieldnotes 2:}

My introduction to the spectacular Adivasi aesthetic practice was marked by glittering mirror-work in the morning sun, women in red and white sari by ponds, graphic bands of contrasting colors painted on ergonomically shaped, clay-clad houses, colorful carved wooden doors and rice-powdered patterns on the façade that spilt onto the roads. By contrast, at first glance, the Hill Sabar seemed bare, even in their aesthetics. Unadorned huts made of locally sourced hay, clay and wood stood sparingly; partially-clad adults and children dressed in weathered clothes and there was a definite lack of color in the surroundings. This challenged my premise of observing occurrence of aesthetic significance amidst 'primitive' realities. But over the months of investigation, it was soon evident that the wanting aesthetic practice was in fact, my lacking perception.

\footnotetext{
${ }^{1}$ Such as daily activity charts, rights, needs and desires, priority listing, participant-led tours and photo-mapping
} 
Aesthetic practices are integral to the Sabar ways of doing, knowing and being furthered through communality and place-making. Such deliberations further our understanding of 'reciprocal learning' in Sabar education, and indicate its relevance in effective mentoring. Some of these constructs had emerged through the mentor- mentee's epistemological and methodological conversations whilst developing the study, others evolved from the field ${ }^{2}$.

\section{Communal significance in Sabar life and education}

Everyday aesthetic practices and ceremonial occasions include a vast array of communal involvement in the Sabar way of life such as hunting, story-telling, play and creating toys, foraging for resources, ceremonial dance and rituals, and creating physical solutions like water irrigation. The significant status of community is made evident from one participant's remarks, 'our culture is to do things sungh-sungh (together as a community). We go on shikar (hunting), take handiya, pray and dance together in these jungles'. The Sabar act as a unified body of individuals who share not only a common language, history and set of values but also new memories, new knowledge, and day-to-day struggles. For instance, all ceremonies (whether of birth, death or marriage) are undertaken by the community as a whole since 'responsibilities when shared enhance joy and prosperity communally, while sorrow is halved'. Furthermore, traditional knowledge alongside new knowledge is shared communally as observed in the case of some Hill Sabar, who adapted the knowledge of solar energy from adjoining Sabar villages to listen to traditional songs on radio.

\section{Fieldnotes 3:}

Through the initial period of my investigations, I observed that even when questions were directed to individuals, Sabar responses were often given in the form of communal conversations or included terms such as Sabar loeg (people) or sungh-sungh (community,

\footnotetext{
2 Emerging constructs that were generated by the site revolved around the role of women in education, rights and responsibilities, concepts of time and space, and the hierarchical nature of knowledge; these are some findings that this paper does not have the capacity to engage with.
} 
together) in expressing personal opinion. But unlike the dominant world's concern for agency, the Sabar individuality was not suffocated or confined by such communality.

The authors consider such communality crucial also for building mentoring relationships. As Deneef (2006) asserts, 'best mentoring relationships are multiple', which necessitate “"community of mentors" who can share responsibility' (p. 231) alongside differing knowledge and 'best practice'.

\section{Sabar Spaces as Self and Place-making}

For the Sabar, their land is a part of their identity, and its environmental knowledge, areas of reliable resources and sacred sites are passed on over generations. Sabar places are defined not only through individual meaning making but a communal one. The community's connection with their landscape spreads naturally into the broader, communal landscape, outside individual territories, and daily activities percolate organically into their surroundings. As one Sabar community leader indicates, a sense of place-making is crucial to their existence (see box 4). Place-making was a construct we wanted to investigate not only due to its unmistakable relevance in the field (Hart, 1979; Burke, 2008; Clark \& Moss, 2005; Eglinton, 2013) but also our personal research experiences ${ }^{\mathrm{ii}}$.

Similarly, place-making and places of learning were equally important for the development of the authors' relationship where conversations were not confined by structures or limited to academia. Richard and Pallawi's personal interest in aesthetic (also in Nature, of being) practice enabled discussions to occur during walks in the college gardens or places outside the system, which strengthened the mentoring relationship.

Fieldnotes 4: 
Investigations into place-making were intended to enable vocalizations and depictions of Sabar physical and liminal places. As one community leader elaborated, 'Sabar know the jungles like we know our grandfather's wrinkled faces. It gives us everything we need, in turn we pray to it, respect it, use only what we need for daily purposes. When we need quiet we play the flute in the jungle, when we are happy, we sing and dance, here'. The Sabar communicated at length about the places where they practiced their flute, played with friends, places of worship or where they learnt a skill, and for "being solitary to think about the future". They projected vivid memories of places as emergent personal spaces, evident from the following: "my place was quiet and breezy; I sat there whilst the cattle grazed"; "under the aam (mango) tree on the banks by the waterfall where I played the flute". In the evenings, the Sabar gather outside their houses or under trees to politicize, confer, play and bond.

\section{Sabar education through the Sabar 'ways of knowing, being and doing'}

Here, we illustrate Sabar priorities, interests, beliefs and values with regards to education made accessible by the study. The Sabar revealed that education was not only about teaching and learning basic survival skills in the forest but also nurturing responsibility towards the community. This is furthered by education about important places in the forests, its resources but also invoking a reverence for their environment, never using more than required. The study made evident people's inclination to learn from and within their physical landscape, which conveyed a freedom in Sabar sense of learning spaces unlike the dark, concrete buildings of current schools. The Sabar learnt by observing, following demonstrations and then, attempting the same themselves. They disclosed their appreciation of the integration of Sabar knowledge and processes in the education system, contextualizing broader curriculum requirements but complained about teachers' lack of motivation and erratic attendance. Some of the people interviewed spoke about their interest in the conventional systems of education but did not want their children to forget Sabar practices and traditions in the making of the "new Sabar". For the majority, the value and purpose of education was related to buddhi (wisdom). Furthermore, they felt it would allow their children to interact with the 'dominant' world with more confidence. Some talked about education as necessary for becoming 
professionals but of the 23 families involved in the study, only one individual equated education to economic or social mobility.

\section{Excerpt 5 - Art and beyond}

Pallawi: "As practitioners of art and education, this is a great occasion to observe aesthetics beyond our paradigm. While Sabar aesthetic production may appear crude to the refined practitioner, Sabar aesthetic significance has relevance in educational thinking and practice, globally."

Richard: "It seems to me that we have an opportunity to test the veracity of the notion that creating and conferring aesthetic significance is an innate human trait that occurs in all societies; this is something that I introduced in Why we Make Art, back in 2005 but as you know, related ideas have been around for some time."

\section{Educational Ecology}

The discussions for this study are ongoing and link dynamically to other areas of investigation, and some may need to be assimilated in further investigations. For the purposes of this paper, we have focused on a central notion that has emerged from examination of Sabar epistemic priorities and practice, which indicates the significance of local knowledge. The study thus offers educational ecology (EE) where educational ideas and systems evolve from its situated understanding. EE urges an education from within its socio-cultural and environmental context and then, from without - the geo-political context, national goals and interrelation aspirations of global mechanics. It is thus informed by local needs and priorities, provoking authentic ideals and sustainable systems of education. Such understanding beckons localization not globalization of education, especially whilst engaging with marginalized minorities. 
Having investigated Sabar people's disengagement from the national systems of formal education and their understanding of education, we note the importance of integrating indigenous knowledge and practices into education in moving towards an educational ecology. Such integration encompasses what the field elsewhere refers to as Vernacular Art Environments -VAE (Rex \& Woywod, 2014), material culture (Somjee, 1999), Visual Material Culture (Eglinton, 2013) or 'living cultural heritage’ (Kurin, 2004). Recognizing local knowledge and values, we believe, would create space for contextualized learning thus authenticating education.

Our observation of EE thus reiterates the notion of decolonization (Thiong'o, 1986; Smith, 2012). By handing over the reigns for their self-realization and recognizing indigenous knowledge we avoid repeating the history of suppressing the 'Other'. This in turn will allow for indigenous social utility and active contribution to society. In addition, if tolerance and critical consciousness are to be developed for future citizenship, education in India can no longer be perceived merely as a means of socio-economic mobility (Sen \& Dreze, 2006; Kumar, 1991). Such an understanding might further benefit the diverse mentee populations in academia, in general.

\section{Concluding remarks}

The authors' personal philosophies draw upon the dissimilarities of the human condition, and the unique social construction that evolves from research communicated through engaging with arts and indigeneity. The potential of arts education we thus reason, emphasizes learners' emerging consciousness by developing a critical perception of 'the way they exist in the world with which and in which they find themselves' (Freire, 1997, p.64); learners come to see the world not as a static reality, but as an inquiry in process. Beyond the barriers of culture, 
gender, power (to its achievable extent), and disparate literacies, such inquiries create a third space (Bhabha, 1994) of dialogue and being. This contiguous space depends primarily on efforts of co-creation, identifying gaps between dialogues and fundamental human creativity. Such systems encourage productive partnerships in education, which 'cannot be mandated but must be left to grow - or not' (Diamond \& Mullen, 1996:13). This understanding of unmandated, organic partnerships and 'sharing' of learning is particularly important where the spaces between the dualities of paradigm or the 'members of the dyad' (Schlosser et al., 2003, p. 187) are vast. Whether this refers to the differences in the context, setting and prior knowledge of the mentor-mentee or the marginalized-dominant, the authors find it essential for future educational relationships.

\section{Excerpt 6 - A 'third space’}

Richard: "What you have done is quite rare in art education - you have gone out into the field as a post-colonial anthropologist, informed by theory derived from areas as diverse as evolutionary psychology, critical theory and ethnomethodology. I have learned a great deal, not just substantive stuff such as Sabar culture, but methodologically too."

Pallawi: "Epistemologically, we had discussed many schools of thought before arriving at postcolonial and socioecological theories. But as we engaged in conversations about the most appropriate and ethical methodology, we agreed upon the paucity of methods eliciting authentic voices and tools that surpassed conventional barriers. Many such research struggles have relied upon your belief in me, constructive advice, and the spaces you created for dialogue beyond hierarchies, formal structures and difference."

\section{References}

Bhabha, H. (1994). The Location of Culture. London, New York: Routledge. 
Burke, C. (2008). 'Play in focus': Children's visual voice in participative research. In P. Thomson (Ed), Doing Visual Research with Children and Young People. Oxon: Routledge. pp. 23- 36.

Clark, A., \& Moss, P. (2005). Spaces to Play: More listening to young children using the Mosaic Approach. London: National Children's Bureau.

Congdon, K. and Blandy, D. (1999). Working with communities and folk traditions: Socially and culturally democratic practice in art education. In D. Boughton, \& R. Mason, (Eds.), Beyond Multicultural Art Education: International perspectives. Munster, New York: Waxmann. pp. 65-83.

Delva, J., Allen-Meares, M. \& Momper, S.L. (2010). Cross-cultural Research. Oxford, New York: Oxford University Press.

Deneef A. L. (2006). Some thoughts on faculty mentoring. In A. L. Deneef \& Goodwin, C. D. (Eds), The Academic's Handbook. Duke University Press. pp. 229-235.

Dewey, J. (2005). Art as Experience. New York: Penguin Books.

Diamond, C.T. P. \& Mullen. C. A. (1996). Beyond the Mentor-Mentee Arrangement: Coauthoring Forms of Post-mentorship. Paper presented at the Annual Meeting of the American Educational Research Association: New York.

Dissanayake, E. (1999). Homo Aestheticus: Where art comes from and why. Seattle, London: University of Washington Press.

Dutton, D. (2009). The Art Instinct: Beauty, Pleasure, and Human Evolution. New York: Bloomsbury.

Eglinton, K. A. (2013). Youth Identities, Localities and Visual Material Culture: Making selves, making worlds. Heidelberg, New York, London: Springer Publishing.

Gandhi, M.K. (1932). India's Case for Swaraj ( $2^{\text {nd }}$ edn). Bombay: Yeshanand \& Co. 
Garfinkel, H. (1963). A Conception of and Experiments With 'Trust' as a Condition of Concerted Stable Actions. In J. O'Brien (Ed, 2011). The Production of Reality: Essays and Readings on Social Interaction, p.379. London: Sage.

Garfinkel, H. (1974). On the Origins of the Term 'Ethnomethodology.' In: R. Turner (Ed.), Ethnomethodology. Penguin, Harmondsworth, pp. 15-18.

Harland, J., Kinder, K., Lord, P., Stott, A., Schagen, I., \& Haynes, J. (2000). Arts Education in Secondary Schools: Effect and effectiveness. Berkshire: National Foundation for Educational Research.

Hart, R. (1979). Children's Experience of Place. New York: Irvington Publishers Inc.

Hickman, R. (2005). Why We Make Art and Why It Is Taught. Bristol: Intellect.

Kumar, K. (1991). Political Agenda of Education: A study of colonist and nationalist ideas. New Delhi, London: Sage Publications.

Rex, L. \& Woywod, C. (2014). Envisioning home, self, and community through vernacular art environments. Art Education, 67:6, 40-46.

Sacks, O. (2008). Musicophilia: Tales of music and the brain. New York: First Vintage Books.

Schlosser, L. Z., Knox, S., Moskovitz, A. R., \& Hill, C. E. (2003). A qualitative examination of Graduate advising relationships: The advisee perspective. Journal of Counseling Psychology, 50:2, 178-188.

Sen, A. \& Dreze, J. (Eds) (2006). Indian Development: Selected regional perspectives. Oxford, New York: Oxford University Press.

Smith, L.T. (1999). Decolonising methodologies: Research and Indigenous peoples. London, New York: Zed Books and New Zealand: University of Otago Press.

Somjee, S. (1999). Learning to be indigenous and being taught to be modern: The ethnography of lessons in art and material culture in Kenya. In D. Boughton, \& R. 
Mason, (Eds.), Beyond Multicultural Art Education: International perspectives. Munster,

New York: Waxmann. pp. 199-211.

Thiong'o, N. (1986). Decolonising the Mind: The politics of knowledge in African literature.

London: James Curry.

Thomson, P. (2008) Doing Visual Research with Children and Young People. Oxon:

Routledge.

\footnotetext{
i The Hill Sabar are part of the indigenous Sabar community who originate from the State of Orissa, and have migrated to West Bengal, Jharkhand and Madhya Pradesh. As the name suggests, Hill Sabar reside in the interior jungles of the hills in East Singhbhum, Jharkhand, unlike their Sabar counterparts who have settled at the foothills, closer to other tribal villages. The Indian Constitution till recently categorised the Sabar peoples as Primitive Tribal Groups to distinguish them from other tribal communities since by comparison they are "primitive, geographically isolated and shy' (National Commission Report, 2005, p. 1). The term was problematic however, and has been amended to Particularly Vulnerable Tribal Group (PVTG). The Sabar, prefer not to be categorised within terms applied generically to the indigenous peoples of India. They claim that they are the descendants of Sugreev and Bali, two mythological characters from the epic prose Ramayan who were princes of a monkey clan, and helped Lord Rama in saving his wife, Sita from the clutches of the evil king, Ravana of Sri Lanka. In this article, where constructs, processes and ideologies are shared by both these communities, the authors apply the term Sabar, differentiating Hill Sabar where these are unique or disparate.

ii Richard's Pallawi's Master's research with the street-children of New Delhi (2012) had ascertained the importance of placemaking
} 